\title{
Wunderkammers: Powerful Metaphors for 'Tangible' Experiential Knowledge Building
}

\author{
Patricia Charlton ${ }^{1}$, Adamantios Koumpis ${ }^{2, *(\mathbb{D})}$, Christos Kouroupetroglou ${ }^{3}$ and Muriel Grenon ${ }^{4}$ \\ Creative Digital Solutions, Witney Lakes Resort, Oxford OX29 0SY, UK; patricia.charlton@pobox.com \\ Faculty of Informatics and Mathematics, Universität Passau, 94032 Passau, Germany \\ UX4ALL, GR54645 Thessaloniki, Greece; chris.kourou@gmail.com \\ Biochemistry, School of Natural Sciences, National University of Ireland, H91TK33 Galway, Ireland; \\ muriel.grenon@nuigalway.ie \\ * Correspondence: adamantios.koumpis@gmail.com; Tel.: +49-152-2775-2484
}

Received: 30 April 2018; Accepted: 19 June 2018; Published: 22 June 2018

\begin{abstract}
Research problem: The paper identifies the need to support powerful metaphors that capture innovations of new emerging human computer interaction (HCI) technologies and innovative question and answering $(\mathrm{Q} \& \mathrm{~A})$ systems in the context of spatial learning and inquiry-based learning in education. Aim/goals of the research: Explore the potential of 'Wunderkammer' (curiosity cabinet) as a powerful metaphor to design new types of learning experiences catering for an ecology of artefacts (real of virtual objects) to provide a holistic context for educators to share and extend learning in action. Conclusions: We provide insight into the emergence of smart interactive objects with different types of sensors that can potentially support everyday life and the increasing access to new visual experiences through augment reality and virtual reality, for new types of tangible knowledge building that can be personalised and shared. This reshaping of human centred design and creating new experiences through tangible creations that externalize in real time and through new materials, the creative power of the 'imaginations of movement' provides new user experience design thinking through the concept of powerful metaphors, to provide core design requirements where the blending of worlds is common place.
\end{abstract}

Keywords: curiosity cabinet interaction metaphor; experiential learning; augmented; mixed and virtual reality; learning artefacts; STEM (Science Technology Engineering Mathematics); arts

\section{Introduction}

The emergence of the curiosity cabinet as a powerful and central metaphor to facilitate spatial inquiry-based learning that provides the design insight into identifying the new blended worlds that are reshaping the knowledge economy, where education is centre stage whether in schools, societies, or work place. Using the lens of education to formalize this metaphor, the paper brings together the emerging innovations and developments in education with the creative technologies to provide an immersive experience of learning about science, technology, engineering, arts, and mathematics (STEAM). This research provides a unique approach, underpinned by the emerging evidence of research and practice from the field of education, of applying the values of 'art' to STEM and going beyond STEAM. The results of an initial investigation through the participation of teachers, students, and communities in the 9 to 12 age group provides the initial design principals. However, it is clear from this analysis and further investigations, both through formal and informal learning cycles, that the curiosity cabinet metaphor as a co-learning experience (process) and personalised learning space (product) can have broader reach and impact. 
This has resulted in the power of the metaphor emerging as a co-designed adaptable toolkit ('The Cabinet') containing all of the necessary tools for communities to design, share, and construct learning experiences. The focus has been to reduce the barrier to access scientific knowledge and processes using the 'art inquiry' of 'aesthetics', which enables an authentic purpose-led problem solving identification, and provides an adaptation of design thinking to provide diversity and inclusion [1]. Aesthetics in the education context brings in three core principles, namely, (a) engagement through curiosity, (b) motivation through inquiry, and (c) ownership through purpose and meaning for the learner. Here, aesthetics in education is authenticity for the learner, drawing on purpose through meaning. This is common practice in the process, and the products of 'art' as the essential ingredients of this method are the inclusion of personal context either in narrative or artefacts. Therefore, ownership sits at the heart of the learning process facilitating engagement and motivation in the complex tasks that are encountered. This property of cross-discipline blending was essential and of central importance for learning in the past centuries, where the curiosity cabinet idea originates. However, learning has, over the last two centuries, been organised into formal academic subjects and disciplines. In modern education, this is often referred to as silos. This silo approach limits the learning about STEM. The lateral thinking to link the cross-discipline relationships is left to the learners. The assumption is to treat the learner as an empty vessel and apply the banking model to teaching and learning [2]. This results in limiting critical and creative thinking and, in the process, limits the possible widening participation by the learners. This, in part, can be addressed if the individual learner context is taken into account. Here technology that supports personalization models aligned with the question and answering (Q\&A) type discourse can assist in overcoming some of the limitations of this traditional model of teaching. While this 'banking model' is not limited to teaching and learning about STEM, it is also worth noting that STEM is frequently taught as a domain devoid of, or very little time is given to, the humanity concerns focusing on facts and inventions rather than societal, ethical, and humanitarian insights. Many innovations in STEM have been driven with the aims of improving the everyday lives of humanity, but its often clinical approach limits the potential of the impact and advancement of society. Without engagement, the learning becomes limited and cannot be sustained towards improving innovation and creative thinking skills. However, we must not devalue STEM, but rather re-shape the way education can engage with the intersection and inclusion of 'meaning' driven learning through this aesthetic lens.

\subsection{Constituents of the Curiosity Cabinet}

\subsubsection{The Interactive Learning Objects}

The interactive learning objects that can be both virtual and real and have tangible and digital properties form a collection of artefacts in the curiosity cabinet. The collection of artefacts can be of general or specialised interest (e.g., a collection of natural science artefacts can have some general interest to the owner/designer of the artefacts, such as engineering or technology). However, the collection may, alternatively, represent some special interest in mathematics. In both cases, the collection of artefacts remain works of art. An example to denote this case may relate to the notion of time, which is an understanding of time from a sciences perspective, how humans created technologies for measuring time, how time can be quantified and measured with a variety of 'devices' (e.g., a mechanical cuckoo clock, a quartz clock, or an atomic clock), and these in parallel to some ancient methods for telling the time, such as the solar clock - the latter may give the opportunity to the educator to lead the learner to some other objects of the curiosity cabinet, which may relate to some other learning subjects.

\subsubsection{The Question and Answering System}

Building on the metaphor of a curiosity cabinet, spatial learning is also enhanced by a novel question and answering (Q\&A) system to help, guide, and trigger inquiry-based learning. This way, students do not only have the opportunity to explore virtual places and objects, but, while doing so, 
they are guided through the Q\&A system to pose/author and search and find answers to student-led questions. This approach builds and draws on the work of Hong, Scardmalia, and Bereiter [3,4], of 'learning with', where the empowerment of the learner is recognized and encouraged. The Q\&A system acts as trigger and a guide for students to explore available and new information, and to find the answers through this process. It is a conversational discourse of exchange. This exploration, in context, in a timely manner, provides the potential for a deeper understanding and for memories to form [5]. Different from 'traditional' question answering (Q\&A) systems (Apple's Siri, Microsoft's Cortana, Google Now, Amazon's Alexa and Facebook's Messenger are among prominent examples), which focus on the provision of final answers in a natural language post-processed form, the curiosity cabinet provides an open-ended experience returning to the user a ranked list of highly relevant semantically related results. This method targets a 'semantic best-effort scenario' [6] that is closer to the information retrieval approaches. This under-pins a contextual exchange and dialogue.

\subsubsection{The Devices}

Spatial learning through the curiosity cabinet metaphor provides learning activities that are distributed across physical space, virtual space, or both. The learners' context, such as in relation to their surroundings, artefacts, and with each other, plays a crucial role in the learning activity. This adaptability of resources, based on the learners' context, provides personalised and collaborative learning experiences. These experiences are adapted to the device that the learners are using. This is possible because the cabinet is highly adaptable to different technologies, varying from low cost (traditional PCs, laptops, tablets, or smartphones) to high-end technological solutions (virtual reality glasses).

The curiosity cabinet metaphor makes explicit the interactive potential of an artefact collection as well as a tool to design different contexts for the individual and the community. In the education context, this provides the means for the different actors to have different configurations to provide both personal and community centered context. The 'power' of the metaphor is the holistic identification of new visual form factors that can be blended using virtual and mixed reality (VR/MR) technologies, which are compatible with a variety of devices, spanning from Microsoft HoloLens (https: //www.microsoft.com/microsoft-hololens/en-us), Oculus Rift (https:/ /www.oculus.com/en-us/), and Samsung Gear VR (http:/ / www.samsung.com/global/galaxy/wearables/gear-vr/), to Google cardboard (https://www.google.com/get/cardboard/) compatible devices, and even simple mobile devices. This provides a means to identify new models of the 'imagination of movement' both in constructing meaning personally and sharing meaning collectively. Furthermore, this concept of an interactive curiosity cabinet includes dynamic processes identifying directly the volatile nature of shared knowledge and understanding, which changes with time. Knowledge and learning are not static processes, hence, a metaphor for designing systems that enable 'tangible' experiential knowledge building must support the agile and changeable nature of such constructions. The choice of devices is not a low-level practicality, as it affects directly and influences the expressive power of the metaphors that are employed, as described in [7,8], in the latter, the concept of embodied space is also introduced, which, if it is underutilized in ubiquitous computing settings and implementations in the past or currently, may be well-exploited in the future, as presented in Section 5 where we refer to the different 'Ubiquitous computing eras'

\subsubsection{Virtual, Mixed, and Augmented Realities}

The term mixed reality is used according to Paul Milgram's classification [9], where mixed reality (or the reality-virtuality continuum) consists of both augmented reality (AR), where the real environment is augmented with virtual objects, and the augmented virtuality (AV), where a virtual environment is augmented with real objects. This research builds on the accessibility of these current and innovate devices to open doors for all learners to experience interdisciplinary and authentic learning through new forms of tangible engagement with STEAM. In the past, interdisciplinary learning used to be closed to everyone, 
except the very few, the mathematicians, scientists, and musicians who could build things in their heads. As Seymour Papert said, in describing his theory of 'constructionism' some 35 years ago, the special thing about building is that it constructs a 'public entity, whether it is a sand castle on the beach or a theory of the universe' [10]. Reflecting on what you have constructed is a key part of learning, knowledge building, and sharing. Until now, this lesson didn't easily translate into learning more generally. But now, with computers, ideas that could only live in the minds of people can have a life on the screen - bringing them alive, and, most importantly, giving people the chance to construct mental representations of dynamic systems alongside virtual ones [11]. Furthermore, now with advancement in VR and MR, these digital environments can provide embodiment experiences. Extending the use of technology enhanced learning environments provides an important spatial experiential learning to be possible, enabling learners to develop explicit and sharable models of their creative insights into science and art. It is worth noting that these tangible experiences are not limited to formal learning at schools. These immersive experiences of embodiment to develop a tactile relationship and physiological understanding of systems have been used to develop and learn about dangerous conditions by formulae one drivers, astronauts, medical operations, etc. This embodied experience (in the sense of [8]) and tangible engagement provides the context for new understandings, which may improve our understanding of the functional value of metaphors. The work of Ritchie [12,13] is relevant and can help deepen our understanding on the active value of metaphors to one area that has been underexplored, namely, the assessment of the efficacy they have as 'vehicles'. This is important when considering the cultural dimension (can the same curiosity cabinet be equally appealing for a young boy in Mali as for a girl in Sweden?). Cultural aspects are discussed in depth in $[14,15]$. However, this is outside the scope of this paper.

\subsection{Principles and Objectives}

The basic principle behind the experiential experience of spatial learning is the idea of embodiment. By enacting learning processes in physical space, which is conveyed to the learners by means of VR and/or MR, learners can investigate entities of a curiosity cabinet in realistic scales, thus dramatically improving the efficacy of the learning process. By engaging in physical motion, they form deeper and more persistent memories of the systems that they explore, and their interactions with others (students, teachers, etc.) in those systems, therefore facilitating learning.

Figure 1 below is adapted from the design thinking process from designthinking.co.nz/designthinking-for-government, and builds on the process thinking that was developed in [6].

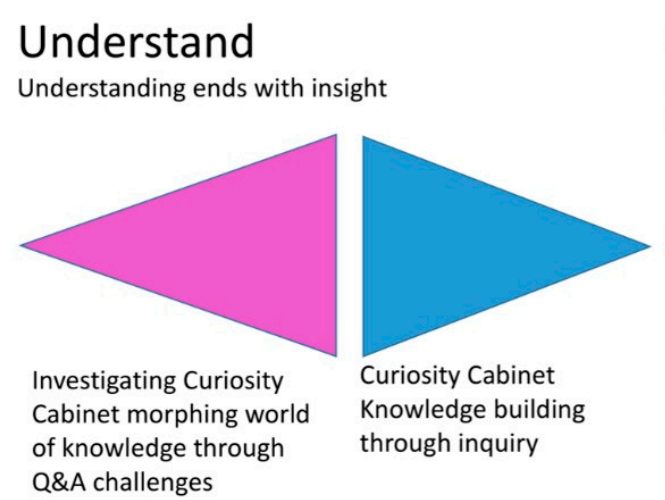

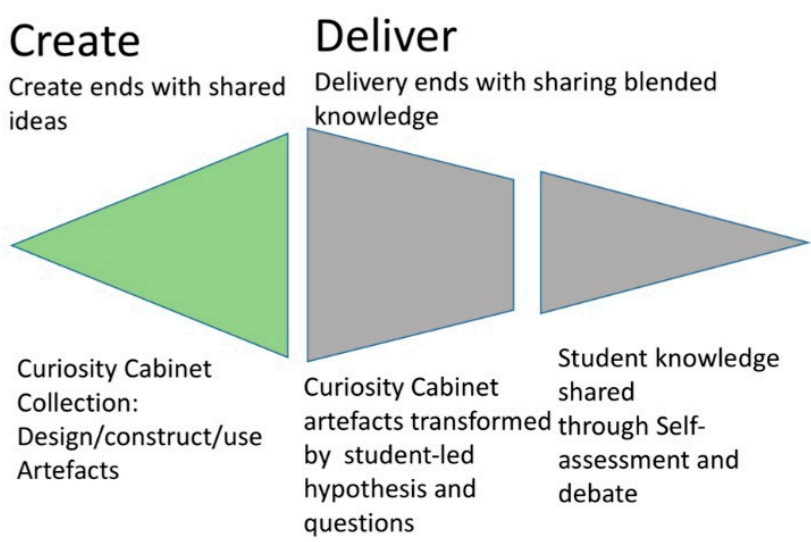

Figure 1. Curiosity cabinet metaphor context as a design thinking process.

In Figure 2, the ecosystem of inventing through community centred internet of ubiquitous computing things (IoUCT [6]) has been mapped to the curiosity cabinet metaphor to illustrate the design thinking process and tangible meaning that is afforded by this metaphor [16]. 


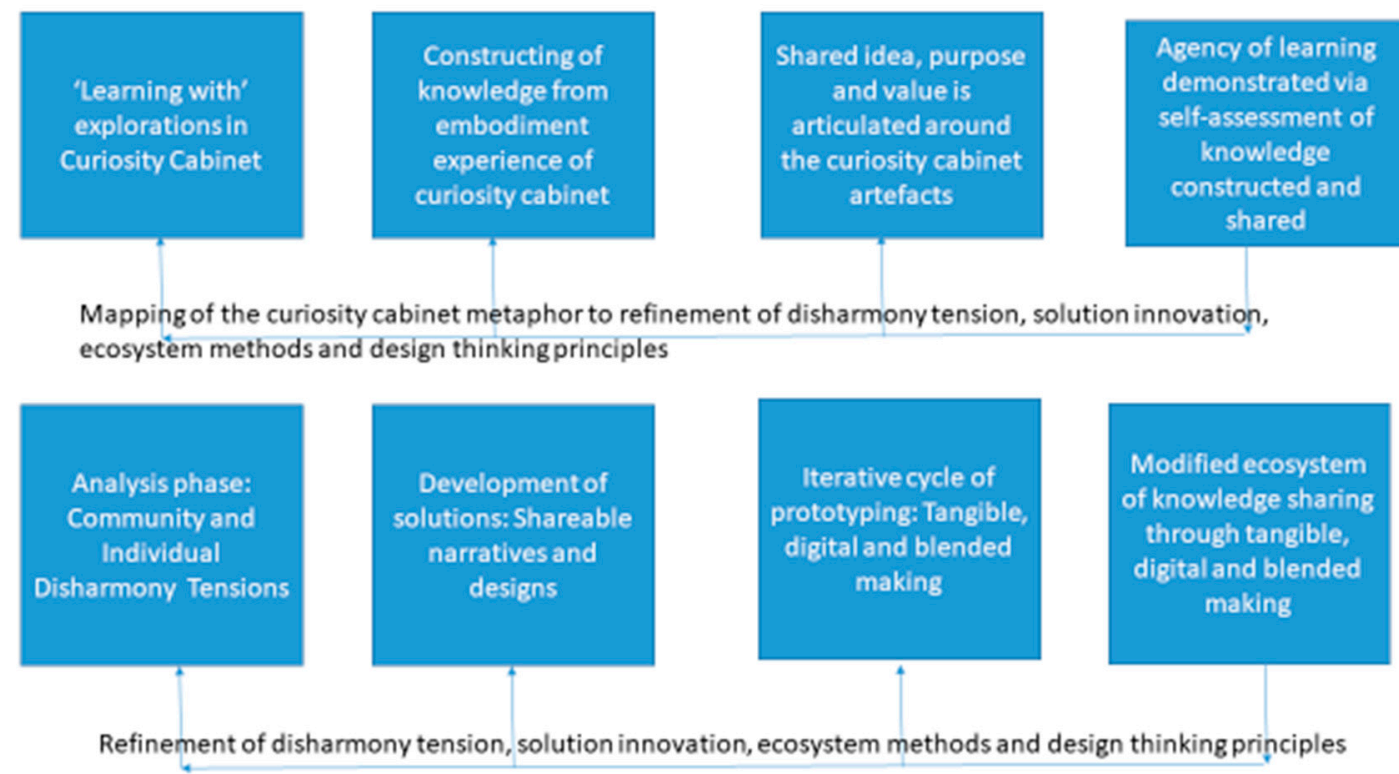

Figure 2. Mapping the curiosity cabinet metaphor to refinement of disharmony tensions, solution innovation, ecosystem methods, and design thinking principles.

Key principles of a powerful metaphor, the curiosity cabinet, as follows:

- Tackling perceived disharmony of understanding through inquiry;

- Connecting the complexity of problematical situations/disharmony in authentic real life settings;

- Enabling diversity from the fact that not only is knowledge never static, but that knowledge also contains multiple interacting perceptions of 'reality';

- Authenticity and student-led context via relevant purposeful activities, relevant, that is, to exploring the situation deeply, and that the ultimate aim is to define and take 'action to improve', which is in the learning context to 'learn with'.

\section{The Main Concept}

The key to the curiosity cabinet metaphor is the principle of spatial learning, which is integrated with inquiry-based learning and is underpinned by appropriate pedagogical principles. The context of theory and practice of spatial learning and inquiry-based learning, as identified by Newcombe [17] and Wai [18], is extended to provide the authentic problem identification, the explicit representation of learning with, and the formulation of pathways to agency of learning. This conceptualization of blending tangible and digital forms in a holistic process of open design processes enables 21st century creativity and critical thinking, and digital literacies skills in STEM education [19]. This knowledge building context for learning combines new interaction technologies (VR/MR, Q\&A, and IoT) and traditional educational concepts of inquiry and spatial learning. As a result, the curiosity cabinet as a central metaphor for learning enables students to do the following:

- Enhance their spatial abilities and spatial thinking, which are both essential for success in STEM education

- Improve their inquiry and critical thinking skills

- Improve their digital competencies by using technological opportunities of the curiosity cabinet environment

- Increase their motivations by using an authentic context for STEM activities

The model is a starting point for developing the learning and teaching materials that form the content and the context of the curiosity cabinet environment. The sections to follow provide the fundamental ideas that are related to the spatial learning aspects of the curiosity cabinet. 


\section{Spatial Learning}

Spatial learning is based on visual landmarks or objects (either virtual or physical) that are available to the student in the form of the virtual or augmented reality. A landmark is a visually salient and distinctive object, which is associated in memory with a specific location, and helps a student to identify his position in the environment. Spatial learning allows students to control parameters or perform experiments using, for example, virtual simulations. The importance of spatial learning is that it relates directly to spatial ability. Spatial ability is a fundamental skill that is linked to future academic success in STEM subjects.

Figure 3 provides an example of the visual blended experience of spatial learning through the curiosity cabinet metaphor. Note that this representation illustrates explicitly the physical and digital experience through the combined tangible artefacts and using augmented reality to interact with different objects. With the advance of smart objects, the potential of the engagement enables the students to be a part of the curiosity cabinet. To sense and feel their surroundings in new forms, to experiment with 'dangerous' materials in a 'safe' yet 'truly' embodied way. As illustrated in Figure 3, the room could have a number of objects on shelves, with one object giving entry into a scenario. Some objects can be placed on shelves and are active artefacts that can be interacted with. The interactivity and purpose are defined initially by start-up STEAM scenarios. However, they are easily adapted by teachers and students when they bring in their own objects to extend the scenarios. As the artefacts are enriched with the user owned, self-defined curiosity objects, queries, co-designing, and co-creation, their curiosity cabinet demonstrates the learning progress. Combining the historical design visual representation with modern objects provides the contextual inquiry cues to develop further interdisciplinary thinking of aesthetics, design, and science. This provides new interactive possibilities for example, the users could touch the object to enter the scenario or manipulate it to activate and interact with the scenario (open a bottle, a box, press a button, twist a ring, etc.).

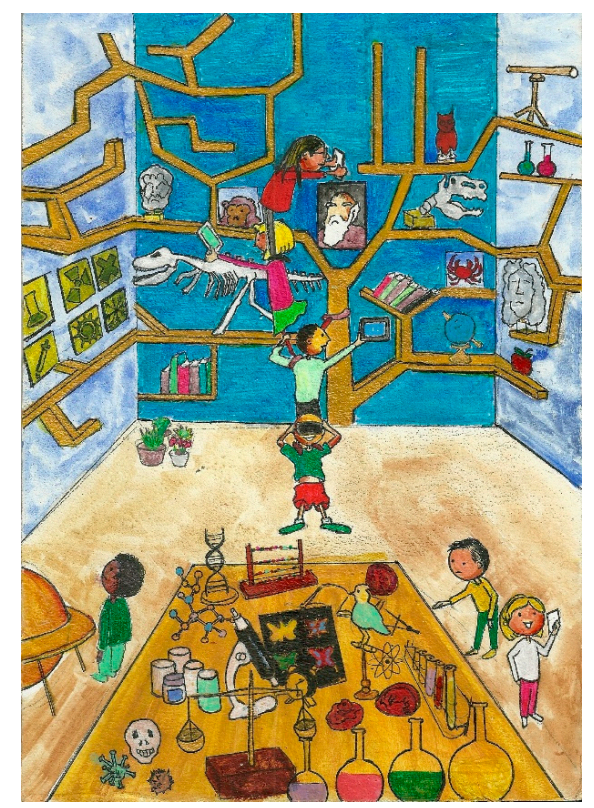

Figure 3. Blending the tangible and digital worlds through the curiosity cabinet (design: Stelios Christoforakis and Charoula Chrysoglou).

Spatial learning environments are settings in which physical or virtual space plays a central role. Learners can explore a virtual space that has been presented to them by mapping it either onto a virtual or physical environment. The virtual environment can be any virtual reality setting, while the physical environment can be a classroom, a sports field, a park, or a (part of a) city or village. For instance: 
- Learners explore the anatomy of cells mapped onto a physical space and play out processes in the cell, such as DNA replication

- Learners engage in a spatial play, enacting physical, chemical, or biological processes in the physical space

- Learners play a historical scientific scenario based on the map of a country or city. Here, even the physical and virtual space can be identical.

The basic principle behind spatial learning is the idea of embodiment. By enacting processes in physical space, students can investigate them in realistic scales. By engaging in physical motion, they form deeper and more persistent memories of the systems that they explore [5]. They engage with the 'imaginations of movement' [20] and are able to provide shared experiences of 'learning with' $[3,4]$.

\section{The Learning Scenarios}

While many educational scenarios tend to revolve around activities that cannot take place in the classroom, an innovation of our approach that is enabled by the curiosity cabinet metaphor is that it allows for its physical implementations in the form of a tangible curiosity cabinet with real world objects forming its artefacts collection. The scenarios that are used to examine and illustrate an artefacts collection use three concepts to demonstrate the variety of technologies of the curiosity cabinet toolkit. Three scenarios that have been provided by the paragraphs below have the following key characteristics:

- To be inquiry-based

- To encourage hands on/active participation

- To be accessible to individual or group of students

- To be multisensorial (at least sound, vision, and touch) to allow for a polysemy that will be reflected, as expected, in the combination of the STEM subjects with arts

- To be portable

- To be adaptable to their usage in both primary school and secondary school setting (primary school focus with secondary school extension or vice versa)

\subsection{Scenario 1: Travel in Time and Space (Virtual and Real Buiding Connected Communities)}

- Concept: Design and create community navigation.

- Implementation of curiosity cabinet: Blended experience of the internet of things. A blended curiosity cabinet filled with tangible and virtual community aspects.

- Entrance to the cabinet: Knowledge building through inquiry, BBC Micro:bit.

- Big curious questions (examples): What are the barriers in modern cities? How can we improve our communities? How do communities connect and share knowledge?

- Use of arts: The curiosity cabinet is a collection of physical designs and virtual artefacts blending tangible and intangible artefacts for new kinds of ecosytems.

- Relates to:

- Science for the key concepts that created modern science, using physical computing, physics, and digital geocaching

- Technology and engineering for the implementation of the means to make it feasible, allow calculations, and new implementation of student centred community solutions

- Mathematics used both for the abstract modelling and the arithmetic calculations.

- Learning outcomes:

- Better understanding of significant scientific discoveries and the context where they happened

- Better understanding of the impact of great scientific discoveries and reshaping communities. 


\section{Example Implementation}

This first case study focuses on students 'learning with' through making, underpinned by the curiosity cabinet metaphor, to let learning emerge and is led by one of the authors within the framework of the nation-wide BBC micro:bit project in London, in the spring term of 2016. A class of year 7 (aged 11 to 12 year olds) worked over six weeks in a cross-curriculum activity between geography and computing designing, and constructing different models and representations of maps and navigation using their shared knowledge and ideas to develop a new understanding about local and global navigation, both old and new, considering local and broader challenges. The study ended with the different design teams presenting their ideas and demonstrating their pilot solutions.

The BBC micro:bit project (http://www.bbc.co.uk/mediacentre/mediapacks/makeitdigital/ micro-bit) started in 2015 in order to provide access to STEAM (science, technology, engineering, art and mathematics) through both formal and informal learning settings. On the one hand, the project focused on providing access to tangible computing and the affordance of computer science in a modern context, on the other hand, it has strong initiatives to bring authentic creative learning experiences through interdisciplinary thinking and problem solving. Strongly influenced by the emerging of maker communities and by the evidence of student engagement in STEAM, through community driven maker spaces, meant that the affordance of the tangible and extensible BBC micro:bit were seen as critical for creating a 'lab in your pocket experience' [1] This 'wearable sharable' extensible device, which is forged by learning through making, brings the context of student-led design with high-tech and low-tech center staged. The curiosity cabinet metaphor enables the pedagogical design of maker communities to illustrate the significance between experiential of building and the internalisation of knowledge through the imaginations of movement.

The case study that is outlined below investigates the potential for tangible tinker media processes in an interdisciplinary context (see Figure 4). Interdisciplinary thinking is a means to stimulate and improve the opportunity for students to apply critical thinking. The application of critical thinking can be more obvious in interdisciplinary settings because the narratives of explanation explicitly draw a correlation and investigation between two domains. Although intuitively there is a relationship between design and creativity and critical thinking that can provide the conditions for potential learner engagement, the explicit dimensions from a pedagogical perspective often remain fragmented and hidden.

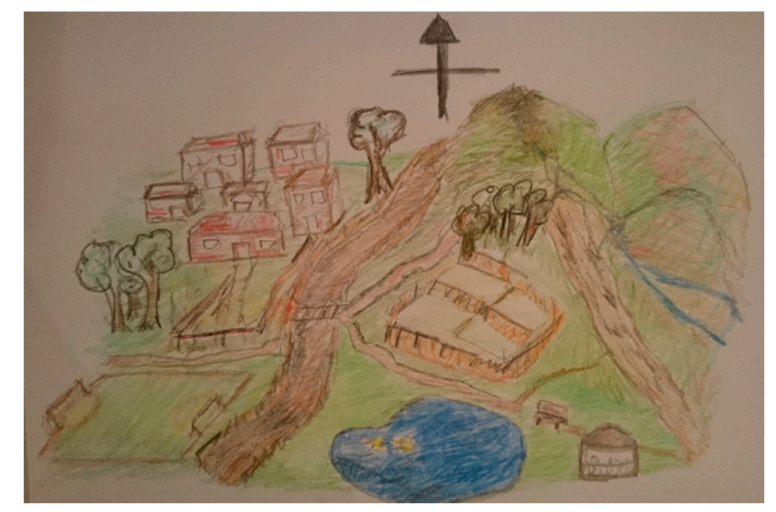

Figure 4. The tangible artefact for sharing (design: year 7 students).

1. The study starts with a discussion about communities and areas that the students know well and what challenges they encounter and what they feel could be improved. The students work in groups and discuss the challenges and what they would like to improve and why. The students discuss the challenges regarding buses e.g., too full, too busy (no seats), safety problems when crossing the roads (lack of crossings), more areas and access to parks and sports, and an easier way to stay connected with friends, to find out what is happening in the community. The students 
design together areas that they know, creating a pictorial representation, and discuss how they would design or change aspects and how changes could be made. Using a thematic approach enables engagement and authenticity about the students' learning, as it has purpose and value to them. Part of the importance of the curiosity cabinet metaphor creates the design affordances of blending Karl Popper's [21] three worlds physical and material reality (World 1), the reality of mental states (World 2), and the third realm (World 3), which encompasses conceptual entities, such as theories and ideas. Addressing concerns by Bereiter [22], mainstream theories of learning are generally too mentalistic and individualistic; they do not usually take into account the fundamental significance of World 3 .

2. They learn about the BBC micro:bit and designing solutions. The students were introduced to the micro:bit and how to program using Touch Develop language and the software environment on micro:bit the https:/ / www.microbit.co.uk/. They continued to work in small groups and discuss their designs, and would then work together as a team to share their thinking. Many interesting ideas emerged as they extended their designs. A number of students commented on enjoying working together. They share ideas and experiment with the different functions. They tried using the accelerometer to build a step counter and test out how this works and whether or not it can be used to count 'people' getting on and off the bus. They use the temperature sensor to collect data about the environment. They investigate creating a timer and different messages together. The students 'learn with' each other and share the knowledge about their findings.

3. These are the ways in which new technologies (micro:bit, see Figure 5) might be used to help in communities looking at a broad set of ideas and designing different ideas: They collaboratively design counting applications, reminders about how to find important places, and ways of sharing new types of messages. Their new message sharing is very interesting because they share programs as messages, with animations and messages contained in their programs. The BBC micro:bit programs are compiled as .hex files that can be imported and/or directly copied onto the micro:bit to run. They started to use the 'texting' programs to share and extend communications that could be displayed on the BBC micro:bit. This idea share in the class 'emerges' as a new personalized communication system that is community driven. With this new innovative approach, they start to design how the physical tangible world blended with digital world can form part of how they 'design connecting' with their local community (see Figure 6). New forms of extending their identities emerge, which contextualizes the learning in an authentic experience. The students investigate and learn about navigation and designing 'hints' in new forms of representations, as the abstract algorithms that they program. They go beyond their navigation and map reading in geography and beyond the programming in computer science, creating a new 'ecosystem' of sharing community knowledge.

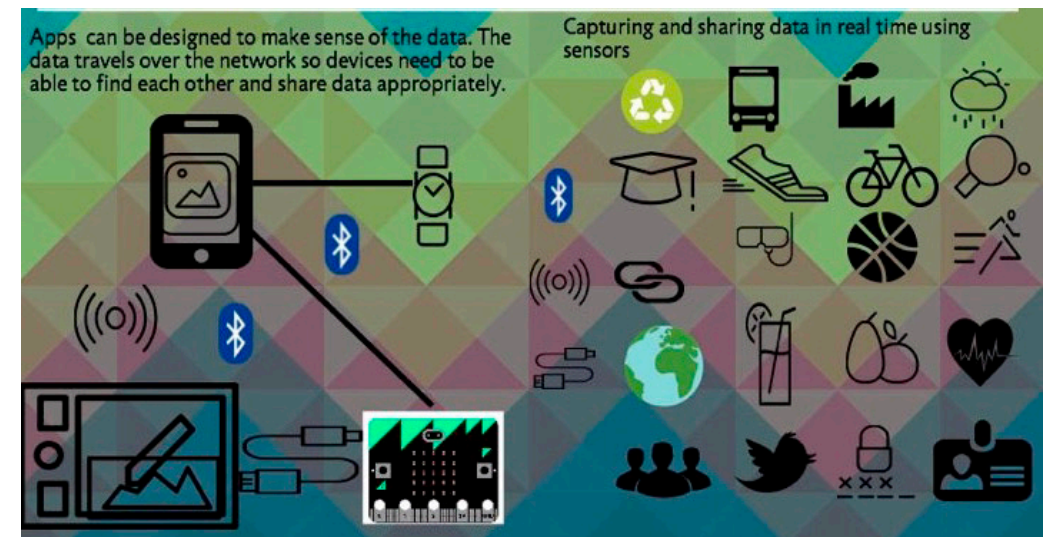

Figure 5. 'Thinking aloud-BBC Micro:bit' ideate/create physical computing with science and art. 
4. Representation of maps and navigation and knowledge building together about history of trade and travel, changes this thought and impact on local and global development. These investigations together and the understanding of maps and exploring leads to the emergence of new ideas of using technology to represent maps. The students bring in their own ideas about community map sharing programs. They start to design a BBC micro:bit caching game and how they can share this using their 'previously' texting programs with messages, and then extending the programs and adding new details.
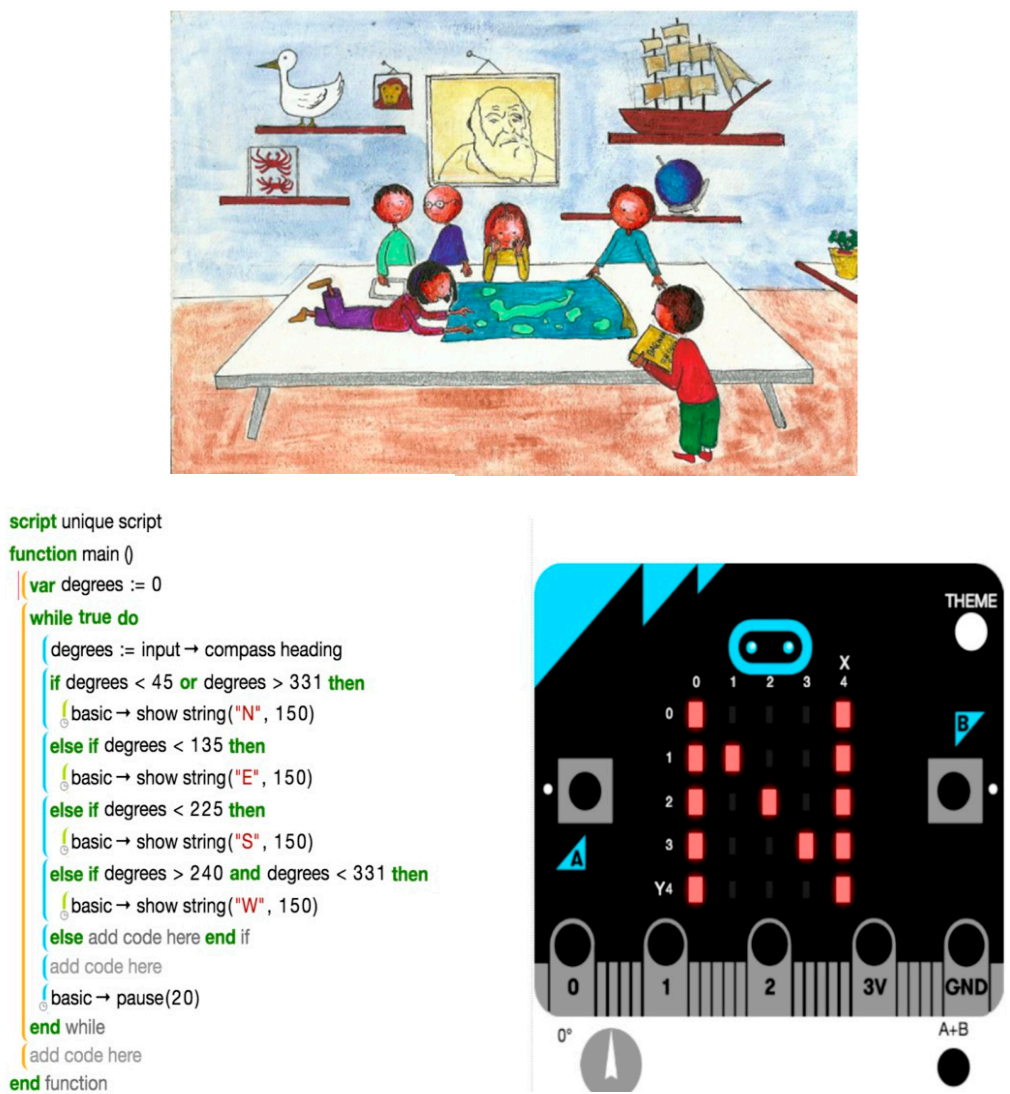

Figure 6. From tangible artefact, to virtual, to physical for sharing (design: year 7 students).

5. The students were creating maps and navigation instructions programming the BBC micro:bit making different types of programs, as follows: The students quickly worked together now, as they have decided that they would like to design a distributed shared community game based on maps and navigation. They create their compass navigation and then start to explore how they can share different maps, both as physical locations, like treasure maps, and virtual maps. Some of the students include ideas from minecraft and other adventure and building games and sharing locations.

6. The geocaching and creating community centered navigation system, as follows: The students designed in their groups different 'geocaching' type challenges. It should be noted that the BBC micro:bit does not have global positioning, so the 'location' is given as hints and treasure type map locations. This language and these messages were designed by the students. Extending geocaching allows for creating community centered engagements and extending new types of navigation messages. The students create quite elaborative programs and messages, creating very specific details and designs to provide new representations of important places and hints. They would exchange these 'program' messages. When a team found the answer, they would send it back in the program. 
7. Presenting their findings and results, (a) their design, and (b) micro:bit caching game: Their understanding of navigation and map reading and co-ordinates has become very efficient, they discussed designing 'map' representations and the importance of a shared understanding of this. This had emerged during their 'map caching challenges', when some message representations could not be understood. All of the students acknowledged each other's' contributions, thus valuing and validating each other's work.

The students' core comment was on seeing maps differently and connecting to the information (see Figure 7). They were able to pick out and read information. Sharing ideas as a group and enjoying the puzzles that each group had set each other, they felt had helped them understand maps and map reading, and the design of the compass and further map programs had provided a better 'tangible understanding' of navigation. The teacher had commented on how they related back to aspects of the experience, they appeared more confident through this very 'tangible context' experience of 'learning with' through making. They all enjoyed playing the new navigation game and tried to be more elaborate at each step of the exchange.

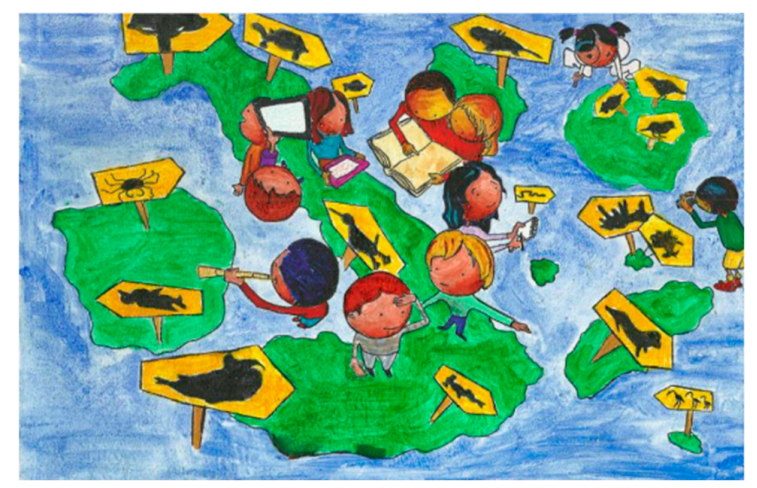

Figure 7. Realisation of the imaginations of movement from ideate to building.

\subsection{Scenario 2: Travel in Another Scale}

- Concept: Change the environment through a change of dimension in scale, time, or place, and be able to evolve in this new environment, aspiring to cover the very small and the very big (i.e., biology, chemistry, and physics).

- Implementation of the curiosity cabinet: Augmented Virtuality. A virtual curiosity cabinet that is augmented with real items attached with information and big curious questions.

- Entrance to the cabinet: Looking at a real artefact through AR device.

- Big curious questions (examples): What are living things made of? How small is a cell? How do cells work? What is common between an egg and a human cell? What can we learn from someone piece of hair?

- Use of arts: The curiosity cabinet is a collection of real artefacts (which could be decorative pieces in students houses).

- Relates to the following:

- Science for the concepts and learning material from biology.

- Technology and engineering for the implementation of the means to make it feasible to allow study of the subjects (evolution from the first types of microscopes to electron microscopes and current scanning technologies, as in the case of the scanning transmission electron microscope, computer simulation).

- Mathematics used both for the abstract modelling and the arithmetic calculations that are necessary to allow for the 'travel in another scale'. 
- $\quad$ Learning outcomes:

- Cells are the smallest unit of life in our body.

- Cells and components-different places do different things.

- Cells belonging to different organs have different shapes.

An Example Implementation

Example: In classroom B, learners have been asked to bring in to class for today's lesson a set of different items, such as a piece of hair, a miniature of a peach, a chicken egg, etc. The teacher brings to the classroom the central artefact, which is a microscope. Using their Google Cardboard headsets and looking at the microscope, the learners are transferred in a virtual curiosity cabinet that includes all of the items they brought in class. They are instructed to look through the microscope to start their quest, in order to answer 'What are living things made of?' They are also informed about the ability to transfer back to the cabinet at any time they need to either get or bring items, and they attach new information, including their own hypothesis and questions, to the items they brought in to class.

When looking through the microscope, they see themselves shrinking in size to the level of human cells. They are now transferred in front of a cell and enter inside it to explore the inner workings. The primary school cell visit will be kept simple and the Q\&A system will act in this scenario as a cell tour guide that curates students through, for example, 'How do cells work?' The tour guide leads the children across the lipid bilayer that makes the cell membrane and acts as a barrier. They travel the viscous cytoplasm and encounter a couple of organelles, namely: the mitochondria, where the cellular energy is generated, and some vesicles that transport cellular constituents or debris. The Q\&A system asks them to identify and explain the different parts that they have encountered and links them with items in the cabinet. Having answered the questions of the tour guide, the students are led to the reticulum endoplasmic and the Golgi, where things are made and packaged, and they move toward the nucleus where the DNA is located. When they pass the nuclear membrane, they discover the DNA packed into chromosomes, and again the Q\&A system engages in conversation through open questions in order to trigger students to search and learn about DNA and its importance for many different aspects of life, connecting them with the existing real items in the cabinet. The chromosome's structure unravels to show the double helix and reveals the basic constitution of this macromolecule. At that stage the children are asked by the tour guide to help make more DNA by the replication method, which is similar to how new cells are made, stimulating potential new ideas and questions from their own hands-on discoveries.

The Q\&A system finishes the tour by leading them back to the cabinet, which in now enriched with all of the information the students have attached to the items through their journey. This is now their gift shop and they attach new challenges of inquiry and open questions so that they can reuse them for future explorations. Teachers can assess through the ending state of the cabinet, the learners' progress and construct new scenarios based on the challenges that have been attached to the objects by the students (see Figure 8).

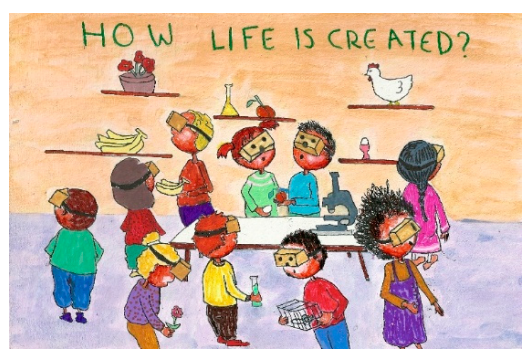

(a)

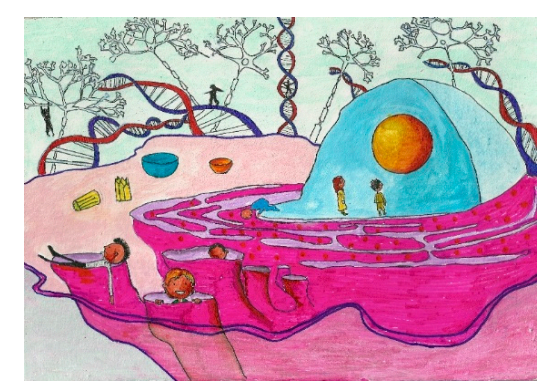

(b)

Figure 8. Cont. 


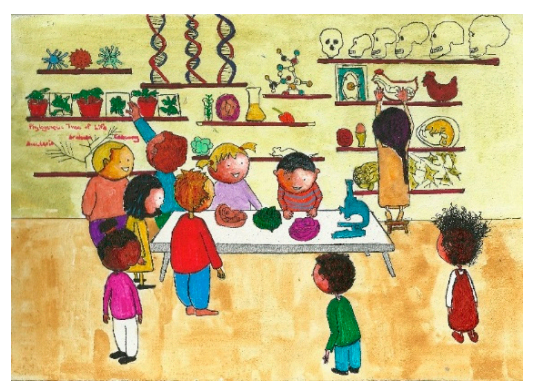

(c)

Figure 8. Clockwise: (a) Before the travel starts: learners prepare for the adventure trying on their equipment; (b) the adventure; and (c) back in the curiosity cabinet (design: Christoforakis and Chrysoglou).

\subsection{Scenario 3: Travel in a Research Laboratory}

- Concept: Manipulations of tools/objects not easily accessible in the classroom.

- Implementation of curiosity cabinet: Augmented reality. A real room acting as the curiosity cabinet, augmented with virtual items attached with information and big curious questions.

- Entrance to the cabinet: Looking at a real artefact through an AR device.

- Big curious questions (examples): How can a scientist get DNA out of living things, for example a banana? What is the role of different chemicals that are used to extract DNA out of cells? How is your toothbrush related with CSI? What is the chemistry of DNA?

- Use of arts: The curiosity cabinet is a collection of real and virtual artefacts (which could be real life items and virtual representations of artefacts, such as a part of a CSI episode).

- Relates to the following:

- Science for the concepts of time and space

- Technology and engineering for the implementation of the means to make it feasible, allow calculations, and potentially allow for its implementation

- Mathematics used both for the abstract modelling and the arithmetic calculations

- Learning outcomes:

- Scientists use different tools to hold and measure components of an experiment

- Follow a protocol to perform a scientific experiment

- The steps needed to extract DNA out of a cell

An Example Implementation

Example: In classroom C, children are walking into a lab room, which acts as the curiosity cabinet. The shelves in the room are filled with pictures, sculptures, miniatures of tools, and a banana in the central table of the room. The students switch on their tablets and smartphones and start the curiosity cabinet app. This is actually allowing them to see the room trough the device's camera that is augmented with virtual objects, properties, and additional information. A seemingly empty bottle through the app is being displayed as a bottle containing alcohol, similar to what they would encounter in a chemistry lab. In this way, the seemingly empty and uninteresting lab augments with a variety of interesting object that can now interact with each other and simulate the environment of a chemistry lab. The Q\&A service starts the students off on their scientific discovery through asking them to examine the banana on the table (see Figure 9). 


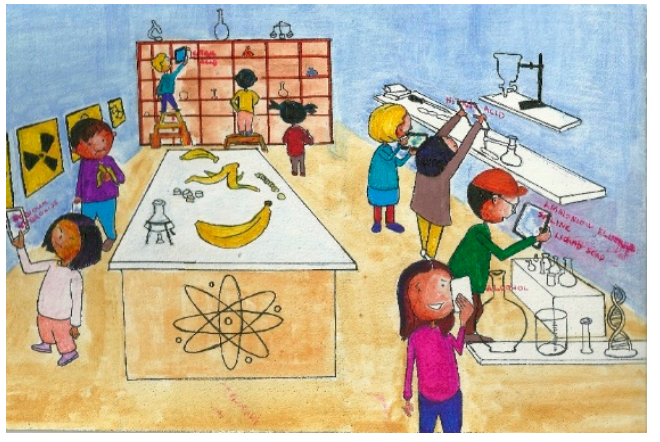

(a)

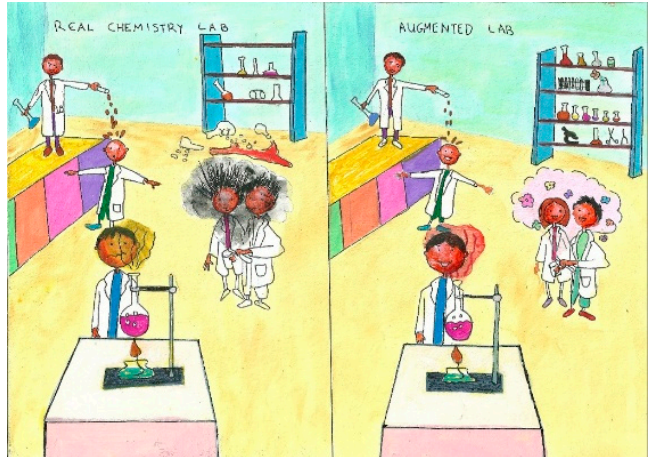

(b)

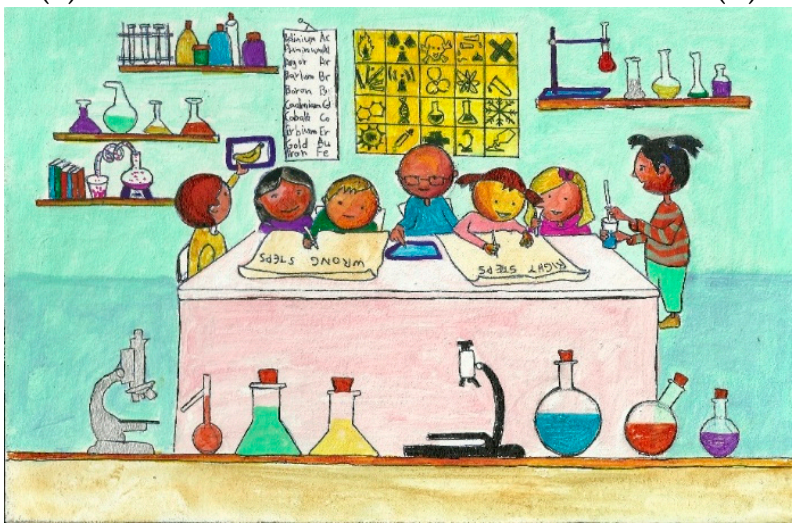

(c)

Figure 9. Clockwise: (a) Preparing for the experiment; (b) the experiment; and (c) discussing after the experiment (design: Christoforakis and Chrysoglou).

This scenario has been adapted slightly from the in the NUI Galway EXPLORERS Programme, presented below briefly in Figure 10b, and shown in action in Figure 10a. The difference is not just that students will not be using the actual process (which requires the attention of professionals in order to ensure the safety of the children handling chemicals) but a simulation through the augmented objects. The actual difference in the application of the pedagogical principles of 'learning with' in the scenario to enable and empower students to discover for themselves and together, which is the right process for extracting the DNA from the banana, rather than instructing them to follow a specific process. The students using their smartphones and tablets working in the augmented lab will be able to try many different options and steps in order to complete the process. The usage of augmented objects allows for errors and accidents to happen, in order to help the students realize the implications of not following the right process, while at the same time guiding them to discover the process themselves.

The system helps them to examine the different processes and to find the right process as well as to understand what went wrong in each case of a failure. During this process, the students will be able to keep the stages of their experiments as new virtual artefacts for the curiosity cabinet and attach information to the various objects in the cabinet, in order to enrich it. Finally, when finishing the experiment, they can revisit the items in the cabinet and attach new challenges, ideas, and hypothesis to specific items of the cabinet to help the teacher both evaluate and create new cabinet experience in the future, using different or similar items in the cabinet. 


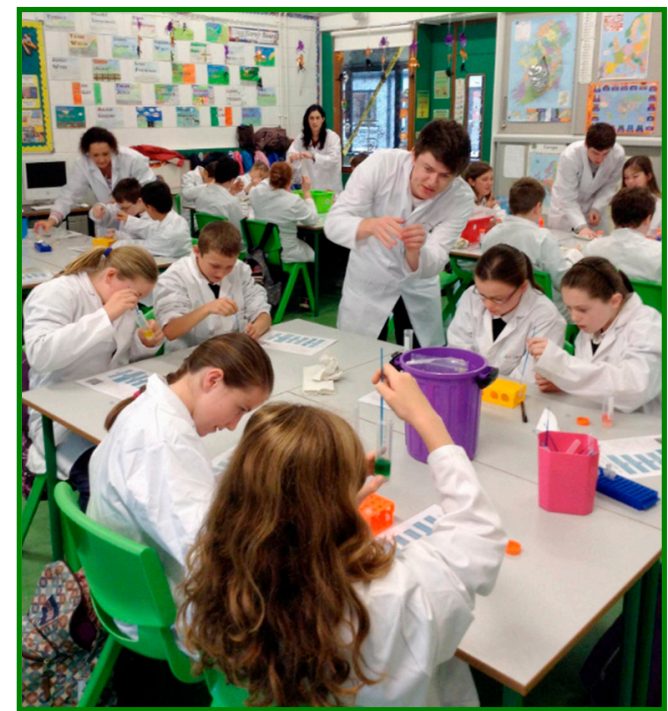

(a)

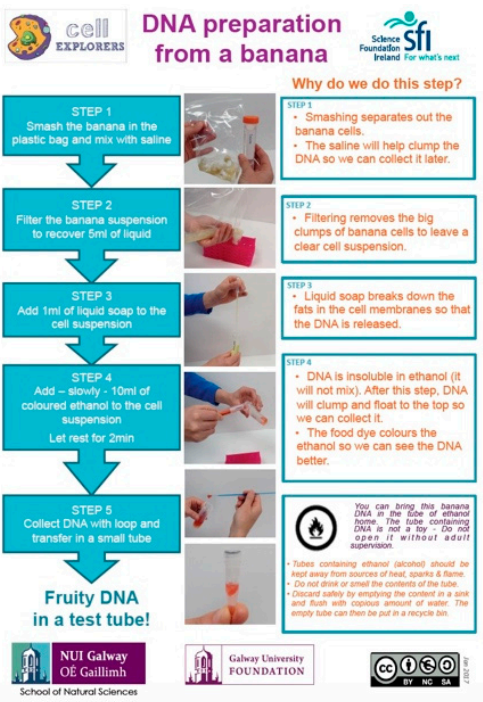

(b)

Figure 10. Clockwise: (a) Class room experimentation organised by the NUIGalway Cell EXPLORERS Programme; and (b) visual protocol as used by Cell EXPLORERS (courtesy of Muriel Grenon and the NUI Galway Cell EXPLORERS Programme).

Below in Table 1 we present, in tabular form, the interplay of virtual and real in the environment and the objects that have been employed for the implementation of the curiosity cabinet metaphor.

Table 1. Blending of virtual and real in the three curiosity cabinet implementations. AR-augmented reality; IoT—internet of things; AV—augmented virtuality.

\begin{tabular}{cccc}
\hline & Scenario 1: IoT & Scenario 2: AV & Scenario 3: AR \\
\hline Virtual: & Environment \& objects & Environment & Objects \\
Real: & BBC Micro:bit & Objects & Environment \\
\hline
\end{tabular}

The choice is not random, that is, the implementation of Scenario 1, regarding travel in time and space, would pose significant difficulties in its realization by means of both augmented reality or augmented virtuality - it would not have easily enabled the students to develop their own community messaging system, and developing new physical/tangible solutions combining technology innovation in new ways.

However, Scenario 2, regarding travel in another scale that is implemented as augmented virtuality, could have been easily implemented with virtual reality but, again, not as part of an augmented reality setting —at least without the loss of several interaction qualities for the implementation of the curiosity cabinet metaphor.

Finally, Scenario 3 for the travel in a research laboratory that is conceived as a case of augmented reality, with the aim to enable children to use objects that are not easily accessible in the classroom, would be possible to offer from within a virtual reality setting, but for obvious reasons not as part of an augmented virtuality.

\section{The Technical Architecture}

In order to tackle the potential compatibility problems between the different devices and technologies, a technical architecture based on cloud-hosted API's taking care of specific parts of a cabinet, is also 
proposed and presented in the following figure. The main component of this architecture, as also presented in Figure 11 below, are as follows:

The Items Collection (IC): A library of virtual or real objects or object representations, accompanied with necessary information, such as provenance, purpose of use, reactions and interaction with other objects, and possible interactions with users. The IC will also operate in the form of an assets library, accompanied by the appropriate API to open access to third party developers that want to include assets and projects under the European Union, which are run by different cultural heritage institutions that have a strategic interest in the use of the concept of the science cabinet to increase their audiences and improve entrepreneurial skills among them.

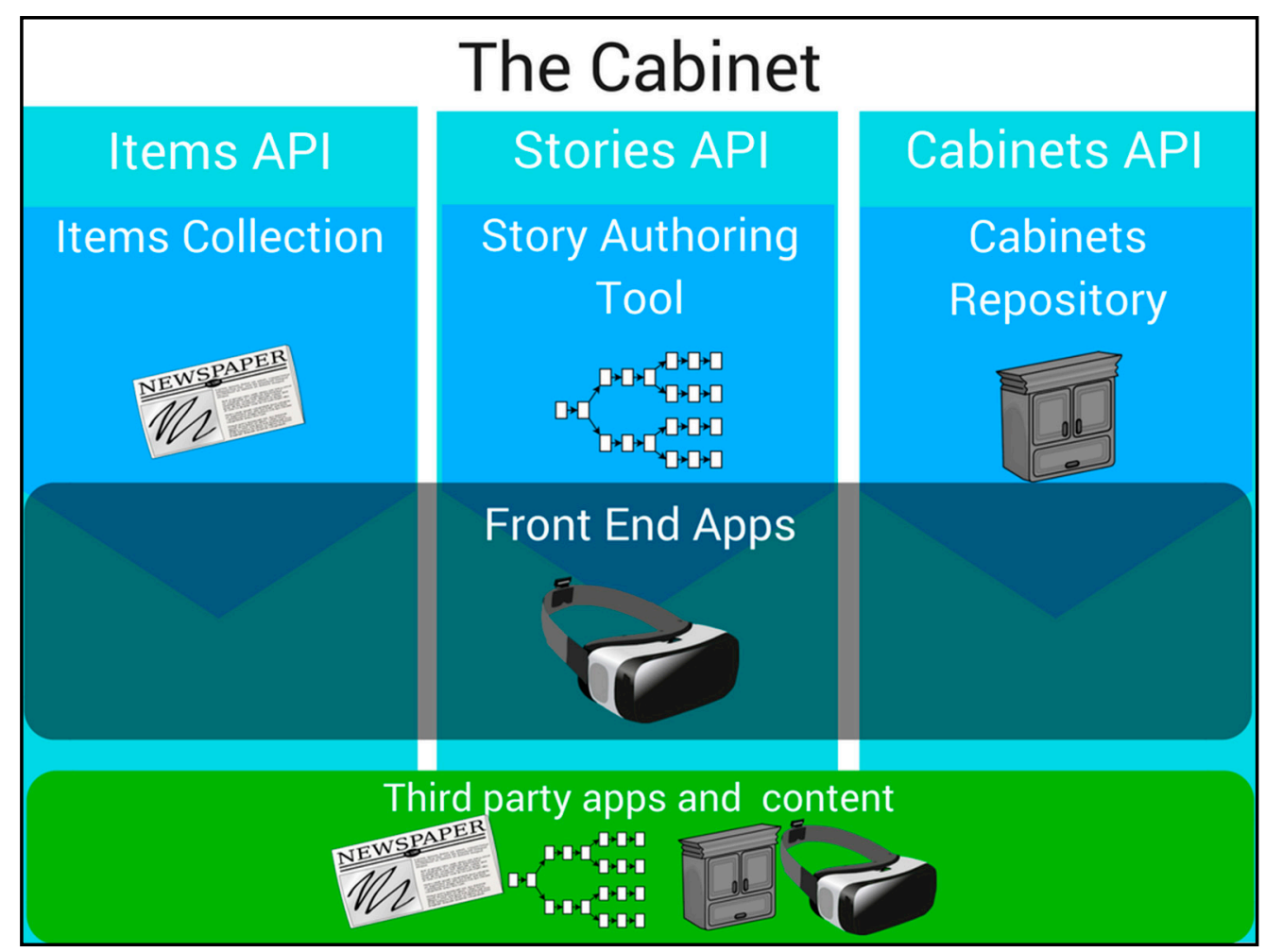

Figure 11. Technical architecture.

The Story Authoring Tool (SAT): A cloud-based tool that will connect with the items collection (IC) and will provide tools to associate those items with related additional information and metadata that will facilitate the collaborative storytelling. The tool will allow its users to include items from the collection within an existing or a new story line and link them with specific key points of the storyline. This tool will be used by citizens in the collaborative storytelling co-creation process and will allow also social interaction elements between users, such as commenting and upvoting specific stories or branches of storylines. SAT will actually be a part of the front-end applications (FEA) that will be presented in the next paragraphs. SAT will be accompanied by the stories API, which will enable creating and managing existing storylines in cabinets, allowing therefore the development of further SAT tools for different devices and with different user interfaces.

The Cabinets Repository (CR): A cloud-based library of cabinets in order for citizens to access cabinets and their related storylines. The cabinets repository will keep information about the different deployments of a cabinet for a specific science theme, allowing this way to create later on aggregations of content, based on the different characteristics of the deployments, such as the event of deployment, the organization that deployed the cabinet, and the place and time of deployment, etc. This way, a collection of different deployments will be created for each science theme, allowing users of higher levels, such as users of 
research organisations or policy makers, to aggregate stories and experience much content-richer cabinets. $\mathrm{CR}$ will also be a part of the FEA that is to be presented in the next paragraph.

CR will be accompanied by the cabinets API, which will enable deploying and managing the deployments of cabinets on a repository, allowing this way the development of further CR and FEA for different devices and with different user interfaces.

The Front-End Applications (FEA): A set of applications including CR and SAT that are designed for different devices, ranging from VR headsets to smartphones and tablets. FEA will adapt the content of a science cabinet to enable citizens and researchers to take appropriate advantage of the technology that is being used. Therefore, the applications provide the appropriate interaction adaptations in order to make use of each device.

The project will focus on developing FEA for VR devices, but will also provide all of the necessary tools through items, stories, and cabinets APIs for third party developers to create their own FEA for additional devices and with their own individual interfaces.

\section{Discussion}

Since the time of Plato, who used the sun, the line, and the cave as metaphors (or allegories or analogies, as other scholars would support) in his Republic, as tools to help him interpret other higher level or more abstract meanings like the notion of God, several researchers and scientists did make use of them as tools or 'facilitators' in their disciplines and areas of research; in all cases, the metaphor is about the nature of ultimate reality and how we come to know it.

The now-classic work 'Metaphors We Live By' of Lakoff and Johnson [23], changed our understanding of the metaphor and its role in language and the mind. Much of the work that has taken place in the field of semantic computing and ontologies traces its roots (Alas! With the semantic researchers and scientists not being aware of this!) to this, now over 35 years old, work.

In this context, the importance of designing powerful metaphors goes beyond the ephemeral aspects of a particular technology. This is easy to see when looking also to more recent bibliography, like [24], which focuses on metaphors in education, metaphors as constituents of multimodal communication $[25,26]$ - which is extremely relevant to our idea of a curiosity cabinet as we approach it in our work and in the article.

In the same way the desktop metaphor is still dominating the idea we have for office computing tasks, the curiosity cabinet may offer a much-sought-after 'portmanteau' vehicle to allow for the smooth transition between the different enabling technologies for ubiquitous computing. To this, the work of Fauconnier and Turner is extremely relevant and related [27], as it is also-at another level though, namely, this of the underlying pragmatics, the work of Brandt [28]. So, as presented in the Table 2 below, the curiosity cabinet instantiations for learning purposes may be implemented with the use of existing technologies that build on Smart Tabs-Pads-Boards, more advanced and emerging ones like Smart Skins-Dust-Clay, or yet-unknown ones or soon-to-appear, which may exploit literally qualities of time, matter, and space, in ways that may go beyond our imagination as of today-which unfortunately, may have been relevant to the ideas of Plato and same as many technical innovations of the last century were conceived by writers of the 18th or the 19th century.

Table 2. Ubiqutous computing (UC) eras.

\begin{tabular}{ccc}
\hline UC $^{\text {in } \text { the Past }} \mathbf{1}^{\mathbf{1}}$ & UC as of Today & UC in the Future \\
\hline Smart Tabs & Smart Skins & Time \\
Pads & Dust & Space \\
Boards & Clay & Matter \\
\hline
\end{tabular}

${ }^{1}$ Mark Weiser, [29,30]. 
What we consider as a novelty in our approach, is that we built on the corpus of metaphors and metaphor design. However, there are similar approaches, equally interesting and with a high value, that appear in the bibliography under the notion of co-design, such as [31,32], and which refer to the application of interaction techniques, such as layered scenario mapping, that build on and expand 'traditional techniques for representing user data in design and results in a map describing a typical scenario along several dimensions and at different levels of abstraction' [31], an aspect that could be implemented with augmented and mixed reality means in our case, or, as it is the case in [32], the use of a pedagogical model to support children's participation in architectural design, where primary school students and university architecture students work in teams to develop their architectural design proposals. A combination of different approaches, such as the ones presented in [31,32], as well as with other ones, may result in supporting users (in our case young students) to explore virtual spaces and extended versions of the real world in a similar fashion as one explores datasets that are appropriately semantically annotated [33].

\section{Conclusions}

Our curiosity cabinet provides a highly individualised learning innovation environment that can adapt to the needs and lifestyle and motivations of the individual learners inquiring together, offering them in full compliance with the original notion of a Wunderkammer with a 'microcosm' and a 'theater of the world' that can be adapted to suit individual interests of the learner, while also be capable to co-evolve to address changes in the interests, in the learning styles or the presentation modalities. The learner is not a consumer of an experience but an equal partner, a 'prosumer', who co-creates both the cabinet and its interaction techniques in terms of e.g., available technological infrastructure (desktops, laptops, tablets, robots, smartphones, VR headsets etc.) and the particular pedagogical parameters (learning and attitudes, pedagogical arrangements, individual and collaborative, group size etc.).

The use of an innovative Question and answering system (Q\&A) based on Big Curious Questions will improve the possibilities of the learners for, amongst others:

- Creating big curious questions of their own

- Obtaining supporting evidence to answer the various questions

- Explaining the evidence that has been collected and connecting the explanation to the knowledge that was obtained from the investigative process

- Creating an argument and justification for each of the provided the explanations

The latter fully justifies the term curiosity, as we do not aim to offer a static collection of resources that may be used for learning (entertainment as well) purposes, but for supporting the active participation of both learners and teachers/educators in the design of learning activities.

Our curiosity cabinet uses virtual, augmented, and mixed reality technologies to provide learners with a multisensory learning experience through these new advanced interface technologies. Learners are supported to interact with real and virtual learning objects, and each other, all of which are part of their own cabinet's collections of artefacts, while they are allowed to visit other learners' or the teacher's/educator's 'institutional' curiosity cabinet. The role of the Q\&A system we employ is essential to the success of the envisaged open innovation ecosystem in two aspects, as follows:

- By reducing the barriers for querying/searching structured data, allowing casual and formal learners to interact directly and easily with sparse and large-schema data using natural language queries, and saving learners from the burdens of representation/vocabulary, and this while we offer easy ('natural') access in multiple European languages.

- By facilitating structured data creation out of structured natural language statements, thus reducing the barriers to data access and helping to increase the value and utilization of the existing open public data as learning resources and assets. 
Applications of our curiosity cabinet can be used both in formal, informal, and non-formal learning settings, and this are also supported by the adaptability to available infrastructure. More specifically, we deploy data under two categories, namely:

- General common sense data such as DBpedia, Freebase, Geonames, and Wikipedia, which are used to maximize the ability of the platform to perform the semantic interpretation of learner's resources and queries

- Domain specific data, which consists of the use of open public data. Both data can be in a structured, semi-structured, or in an unstructured format.

The curiosity cabinet facilitates also networking by allowing groups of learners to participate in common learning experience, and for educators to cooperate in developing sessions that may suit a variety of both formal and informal education needs. Moreover, as a network of cross-sector partners in Europe, we view non-formal, informal, and formal learning on a spectrum, with non-formal learning on the one end and formal learning on the other, although we believe that most learning can be a mixture of both. This reflects the diversity of our different sectors and the facilitating role that technology can play.

Author Contributions: M.G. developed the learning scenarios; C.K. developed the augmented-mixed-virtual reality parts; A.K. conceived and organized the curiosity cabinet metaphor; and P.C. provided the learning background and the spatial learning context.

Funding: Parts of the work reported in the paper has been financed through the Cell EXPLORERS Programme funded by NUI Galway, the Galway University Foundation and by Science Foundation Ireland under its Discover Programme.

Acknowledgments: Stelios Christoforakis and Charoula Chrysoglou, Faculty of Fine Arts, School of Visual and Applied Arts of the Aristotle university of Thessaloniki, Greece conceived and developed the pictures based on our text. We thank them both! All of the visual aspects and properties of the drawings are their intellectual property. We would like to also express our thanks to the two anonymous reviewers and the editor and the management team from the journal for the kind help, the useful comments, the constructive criticism, and the suggested improvements they have provided us with.

Conflicts of Interest: The authors declare no conflict of interest.

\section{References}

1. Charlton, P.; Poslad, S. A Sharable Wearable Maker Community IoT Application. In Proceedings of the 12th International Conference on Intelligent Environments, London, UK, 14-16 September 2016.

2. Freire, P. Education for Critical Consciousness; Bloomsbury: London, UK, 1974.

3. Hong, H.Y.; Scardamalia, M.; Messina, R.; Teo, C. Principle-based design to foster adaptive use of technology for building community knowledge. In Proceedings of the 8th International Conference of the Learning Sciences (ICLS'08), Utrecht, The Netherlands, 24-28 June 2009; Volume 1, pp. 374-381.

4. Scardamalia, M.; Bereiter, C. A Brief History of Knowledge Building. Can. J. Learn. Technol. 2010, 36, 1-16. [CrossRef]

5. Johnson-Glenberg, M.C.; Birchfield, D.A.; Tolentino, L.; Koziupa, T. Collaborative embodied learning in mixed reality motion-capture environments: Two science studies. J. Educ. Psychol. 2014, 106, 86-104. [CrossRef]

6. Poslad, S.; Charlton, P. The Internet of Ubiquitous Computing Things for Anytime, Anywhere, Anything, Anyone Inventions. Mob. Inf. Syst. 2016. under review.

7. Brandt, L.; Brandt, P.A. Making sense of a blend: A cognitive semiotic approach to metaphor. Annu. Rev. Cogn. Linguist. 2005, 3, 216-249. [CrossRef]

8. Fahlenbrach, K. The emotional design of music videos: Approaches to audiovisual metaphors. J. Mov. Image Stud. 2005, 3, 22-28.

9. Milgram, P.; Takemura, H.; Utsumi, A.; Kishino, F. Augmented Reality: A class of displays on the realityvirtuality continuum. In Proceedings of the Telemanipulator and Telepresence Technologies, Boston, MA, USA, 31 October-1 November 1994; pp. 282-293.

10. Papert, S. Mindstorms: Children, Computers, and Powerful Ideas; Basic Books: New York, NY, USA, 1980. 
11. Luckin, R.; Bligh, B.; Manches, A.; Ainsworth, S.; Crook, C.; Noss, R. Decoding Learning: The Proof, Promise and Potential of Digital Education; Nesta: London, UK, 2012.

12. Fahlenbrach, K. Embodied spaces: Film spaces as (leading) audiovisual metaphors. In Narration and Spectatorship in Moving Images; Anderson, J.D., Anderson, B.F., Eds.; Cambridge Scholar Press: Cambridge, UK, 2007; pp. 105-124.

13. Ritchie, D. Common ground in metaphor theory: Continuing the conversation. Metaphor Symb. 2004, 19, 233-244. [CrossRef]

14. Ritchie, D. Metaphors in conversational context: Toward a connectivity theory of metaphor interpretation. Metaphor Symb. 2004, 19, 265-287. [CrossRef]

15. Littlemore, J. The effect of cultural background on metaphor interpretation. Metaphor Symb. 2003, 18, $273-288$. [CrossRef]

16. Kovecses, Z. Metaphor in Culture: Universality and Variation; Cambridge University Press: Cambridge, UK, 2005.

17. Newcombe, N.S. Picture This: Increasing Math and Science Learning by Improving Spatial Thinking. Am. Educ. 2010, 34, 29-43.

18. Wai, J.; Lubinski, D.; Benbow, C.P. Spatial Ability for STEM Domains: Aligning Over 50 Years of Cumulative Psychological Knowledge Solidifies Its Importance. J. Educ. Psychol. 2009, 101, 817-835. [CrossRef]

19. European Commission/EACEA/Eurydice. Developing Key Competences at School in Europe: Challenges and Opportunities for Policy; Eurydice Report; Publications Office of the European Union: Luxembourg, 2012. Available online: http:/ / keyconet.eun.org/c/document_library/get_file?uuid=d21d041b-ea4e-448e-954b58e4272b194c\&groupId=11028 (accessed on 27 March 2018).

20. Chandrasekharan, S. Building to Discover: A Common Coding Model. Cogn. Sci. 2009, 33, 1059-1086. [CrossRef] [PubMed]

21. Popper, K. Three Worlds. The Tanner Lecture on Human Values; The University of Michigan: Ann Arbor, MI, USA, 1978. Available online: https://tannerlectures.utah.edu/_documents/a-to-z/p/popper80.pdf (accessed on 24 April 2018).

22. Bereiter, C. Education and Mind in the Knowledge Age; Erlbaum: Hillsdale, NJ, USA, 2002.

23. Lakoff, G.; Johnson, M. Metaphors We Live By; University of Chicago Press: Chicago, IL, USA, 1980.

24. Hardie, A.; Koller, V.; Rayson, P.; Semino, E. Exploiting a semantic annotation tool for metaphor analysis. In Proceedings of the Corpus Linguistics 2007 Conference, Birmingham, UK, 27-30 July 2007.

25. Cameron, L. Metaphor in Educational Discourse; Continuum: London, UK, 2003.

26. Forceville, C. Cognitive linguistics and multimodal metaphor. In Bildwissenschaft: Zwischen Refl Ektion und Anwendung; Sachs-Hombach, K., Ed.; Von Halem: Cologne, Germany, 2005; pp. 264-284.

27. Forceville, C. Non-verbal and multimodal metaphor in a cognitivist framework: Agendas for research. In Cognitive Linguistics: Current Applications and Future Perspectives; Kristiansen, G., Achard, M., Dirven, R., de Mendoza Ibanez, F.J.R., Eds.; Mouton de Gruyter: Berlin, Germany, 2006; pp. 379-402.

28. Fauconnier, G.; Turner, M. Rethinking metaphor. In The Cambridge Handbook of Metaphor and Thought; Gibbs, R.W., Ed.; Cambridge University Press: New York, NY, USA, 2008; pp. 53-66.

29. Weiser, M. The computer for the twenty-first century. Sci. Am. 1991, 265, 94-104. [CrossRef]

30. Poslad, S. Ubiquitous Computing: Smart Devices, Environments and Interaction, 1st ed.; Wiley: Chichester, UK, 2009; pp. 1-40.

31. Freitas, A.; Carvalho, D.S.; da Silva, J.C.P.; O’Riain, S.; Curry, E. A Semantic Best-Effort Approach for Extracting Structured Discourse Graphs from Wikipedia. In Proceedings of the 1st Workshop on the Web of Linked Entities (WoLE 2012) at the 11th International Semantic Web Conference (ISWC), Boston, MA, USA, 11-15 November 2012.

32. Lurås, S. Layered scenario mapping: A multidimensional mapping technique for collaborative design. CoDesign 2016, 12, 133-150. [CrossRef]

33. Lozanovska, M.; Xu, L. Children and university architecture students working together: A pedagogical model of children's participation in architectural design. CoDesign 2013, 9, 209-229. [CrossRef]

(C) 2018 by the authors. Licensee MDPI, Basel, Switzerland. This article is an open access article distributed under the terms and conditions of the Creative Commons Attribution (CC BY) license (http://creativecommons.org/licenses/by/4.0/). 